\title{
СУЩНОСТНЫЕ ХАРАКТЕРИСТИКИ ПРОЕКТНО-ЦЕЛЕВОГО ПОДХОДА В РАЗВИТИИ ДОПОЛНИТЕЛЬНОГО ОБРАЗОВАНИЯ
}

\author{
B. 3. Юсупов \\ Московский гуманитарный университет
}

\begin{abstract}
Аннотация: В статье раскрываются сущностные характеристики проектно-целевого подхода как эффективного механизма развития дополнительного образования в современном вузе; особенности целевого образовательного проекта, источников его финансирования, ресурсов разработки и реализации.
\end{abstract}

Ключевые слова: проектно-целевой подход; целевой образовательный проект; дополнительное профессиональное образование

\section{ESSENTIAL CHARACTERISTICS OF THE PROJECT-TARGET APPROACH IN THE DEVELOPMENT OF SUPPLEMENTARY EDUCATION}

\author{
V. Z. Yusupov \\ Moscow University for the Humanities
}

Abstract: The article reveals the essential characteristics of the project-target approach as the most effective mechanism for the development of supplementary education in a modern university. The author demonstrates the features of the target educational project, its sources of funding, development and implementation resources.

Keywords: project-target approach; target educational project; supplementary vocational education

Развитие дополнительного образования входит в число приоритетных направлений развития современного образовательной организации высшего образования. Анализ научного контекста этой проблемы показывает разнообразие методологических подходов к её решению, в числе которых различные варианты обозначения проектного подхода, имеющие общую гносеологическую основу, но различающиеся совокупностью способов, приёмов, процедур, используемых для его реализации. В числе таких вариантов чаще всего называется проектно-программный (программно-проектный), проектно-целевой (программно-целевой), проектно-модульный (программно-модульный) подходы. Различие в названиях, чаще всего, определяется авторской позицией в отношении использования слов программа, 
проект и целевой проект. Одни исследователи концентрируют внимание на образовательной программе нормативно-управленческом документе, первоначально представленном в форме проекта; другие видят в программе разновидность проекта, для третьих программа - это совокупность взаимосвязанных проектов, объединённых стратегической целью.

В ряде исследований (преимущественно в кандидатских диссертациях) предпринимаются попытки обоснования новых модификаций проектного подхода, например таких, как проблемно-проектного, вариативно-программного и т. п. Однако, внимательный анализ содержания этих работ показывает, что они представляют собой лишь интерпретацию одного трёх названных вариантов обозначения проектного подхода.

Термин «проектно-целевой подход» используется в педагогической науке и практике последние 10-15 лет. С точки зрения И. А. Колесниковой и М. П. Горчаковой-Сибирской, он обеспечивает организацию проектирования в соответствии с заданной целью посредством реализации целевых проектов, имеющих конкретного заказчика, в лице которого чаще всего выступают «административные (государственные, территориальные) органы или организации, владеющие необходимыми проектными ресурсами» (Колесникова, 2005: 30). С такой позицией можно согласиться лишь отчасти, поскольку она отражает частный случай осуществления проектно-целевого подхода на уровне взаимодействия органов исполнительной власти различного уровня и образовательных учреждений.

Региональный аспект такого взаимодействия рассматривается в докторской диссертации И. Г. Голышева «Управление интеграцией региональных рынков труда и образовательных услуг в сфере высшего профессионального образования» (Голышев, 2012). Автор в качестве основного методологического подхода к решению этой проблемы как раз использует проектно-целевой подход, характеризуя его в качестве общей методологии распределения ресурсов на достижение конкретных целей. «Подготовка современного специалиста на основе проектно-целевого подхода, - отмечает И. Г. Голышев, - это совместная практико-ориентированная деятельность образовательных учреждений, профессионального сообщества и органов власти, направленная на решение текущих и перспективных задач в сфере кадрового обеспечения производства. Соответственно, постановка проективных целей происходит на основе комплексного учёта потребностей и интересов вузов, работодателей и государства в условиях социально-экономического развития конкретного региона» (там же: 13 ).

В последние годы появляются исследования, выполненные в области экономики и управления народным хозяйством, которые посвящены исполь- 
зованию методологии проектного управления для решения средствами образования экономических и социальных проблем регионального развития. Наиболее наглядным примером может служить диссертационное исследование А. А. Голодовой, основанное на использование проектного подхода к разработке программ начального профессионального образования в регионе (Голодова, 2010). В этой и других работах называется, но обстоятельно не раскрывается методологии проектного управления или, как её ещё называют - проектная методология, методология управления проектами.

В педагогической науке и практике явно назрела необходимость осуществления специального исследования методологии проектного управления. Её отдельные положения начали разрабатываться авторами диссертационных исследований и монографий, но пока в качестве аспекта проблематики их собственных исследований (К. С. Бажин, А. И. Богданов, Т. Г. Волченкова, А. А. Голодова, В. З. Юсупов и др.).

С точки зрения автора настоящей статьи проектно-целевой подход в педагогике представляет собой способ организации проектной деятельности, который реализует идею разработки и реализации целевого проекта и представляет собой совокупность конкретных методов, составляющих их операций, приёмов, правил применения, ориентированных на решение как отдельных (частных) так и совокупностей задач удовлетворения образовательных потребностей определённых групп заказчиков и потребителей образовательных услуг.

В характеристике проектно-целевого похода, как и любого другого, прежде всего, следует выделить его смыслообразующее понятие - целевой проект. Оно используется в различных отраслях научного знания и практики - менеджменте, экономике, социологии, культурологи, где чаще всего обозначает проект, который нацелен на удовлетворение потребностей конкретной социальной группы (групп) и даже отдельных юридических или физических лиц, которые могут выступать в качестве его заказчика.

В современной образовательной практике разработка и реализация целевых проектов чаще всего связана с выполнением образовательными учреждениями государственного или муниципального задания на оказание образовательных услуг определённым группам населения. Это могут быть определённые категории детей; студенты колледжей и вузов, обучающиеся на основе целевого приёма за счет бюджетных ассигнований федерального бюджета, бюджетов субъектов Российской Федерации и местных бюджетов; отдельные категории граждан, профессиональное образование или профессиональная переподготовка которых осуществляется за счёт субсидий бюджетов различного уровня (например, безработные граждане, со- 
Научные труды Московского гуманитарного университета 2019 № 4

стоящие на учёте в службах занятости населения и т. д.). Организационной формой реализации такого задания вполне может стать целевой проект.

Государственное задание - это нормативный документ, который устанавливает показатели, характеризующие качество и (или) объём (содержание) государственной услуги (работы), порядок её оказания и контроля за исполнением, а так же требования к отчётности об исполнении государственного задания. На основе государственного (муниципального) задания (заказа) осуществляется государственное и муниципальное финансирование реализации образовательных программ. Государственное задание в сфере образования (образовательный заказ) имеет две формы. Первая это государственный заказ-задание - поручение органов государственной власти государственным образовательным организациям на обязательное оказание образовательных услуг гражданам Российской Федерации в соответствии с государственной образовательной политикой. Вторая форм представляет собой государственный образовательный заказ-соглашение - соглашение между органами государственной власти, с одной стороны, и образовательными организациями, с другой стороны, об оказании образовательных услуг гражданам Российской Федерации, проживающим на территории её региона.

Наиболее эффективной организационной формой выполнения государственного задания как раз и является целевой образовательный проект. Его заказчиками чаще всего являются становятся региональные органы власти и управления, а так же подведомственные им учреждения, которые наделены правами проведения конкурса проектов на оказание дополнительных образовательных услуг для государственных и муниципальных нужд. В лице заказчиков целевых проектов выступают также различные фонды, крупные предприятия и организации. Таким образом, образовательный проект может рассматриваться как целевой, если он имеет конкретного заказчика и осуществляется за счёт его финансовых ресурсов.

Рассмотрим особенности проектно-целевого подхода в организации дополнительного профессионального образования в вузе. В соответствии с федеральным законом «Об образовании в РФ» «дополнительное профессиональное образование направлено на удовлетворение образовательных и профессиональных потребностей, профессиональное развитие человека, обеспечение соответствия его квалификации меняющимся условиям профессиональной деятельности и социальной среды» (ст. 76, см.: Об образовании ..., Электр. ресурс).

Дополнительное профессиональное образование реализуется посредством двух видов образовательных программ. «Программа повышения ква- 
лификации направлена на совершенствование и (или) получение новой компетенции, необходимой для профессиональной деятельности, и (или) повышение профессионального уровня в рамках имеющейся квалификации. Программа профессиональной переподготовки направлена на получение компетенции, необходимой для выполнения нового вида профессиональной деятельности, приобретение новой квалификации» (там же).

Эти программы реализуются образовательными организациями профессионального образования и организациями дополнительного профессионального образования. Для последних образовательная деятельность по таким программам является их основной целью. Для образовательных организаций профессионального образования в качестве основной цели их деятельности выступает образовательную деятельность по образовательным программам профессионального образования и научная деятельность. Вместе с тем, объём осуществляемого в них дополнительного профессионального образования постоянно растёт, что связано с расширением спектра образовательных услуг, которые они оказывают

В нормативных документах под образовательной понимается услуга, оказываемая организацией, осуществляющей образовательную деятельность, или индивидуальным предпринимателем по организации и осуществлению образовательного процесса (обучения) в целях освоения обучающимися образовательных программ или программ отдельных учебных курсов, предметов, дисциплин (модулей). Авторы, педагогического словаря, изданного под редакцией В. И. Загвязинского и др., считают, что образовательная услуга - это «понятие, характеризующее превращение в рыночных условиях знаний, навыков и умений в товар, служащий удовлетворению тех или иных потребностей потребителей. Такой подход, отмечается в словаре, правомерен только в экономическом аспекте, так как не отражает культурологическую сущность образования» и воспринимается в педагогической теории и практике неоднозначно (Педагогический словарь, 2008: 37).

С точки зрения В. А. Лукова образовательная услуга представляет собой результат полезной деятельности отдельных лиц, а так же организаций, направленной на удовлетворение определённых потребностей. Учёный отмечает, что приобретение знаний, умений и навыков характерно для любого социального проекта и считает оказание дополнительной образовательной услуги основной целью социально-проектной деятельности (Луков, 2003: 39, 540).

Анализ современной практики работы вузов показывает, что они активно стремятся предоставлять разнообразные дополнительные образовательные услуги, в том числе в рамках целевого повышения квалификации и 
профессиональной переподготовки работников, деятельность которых связана с обеспечением государственных и муниципальных нужд. Реализация таких услуг преимущественно осуществляется в соответствии с Федеральным законом № 44-Ф3 «0 контрактной системе в сфере закупок товаров, работ, услуг для обеспечения государственных и муниципальных нужд», который определяет, что «контрактная система - это совокупность её участников и осуществляемых ими действий, направленных на обеспечение государственных и муниципальных нужд» (ст. 3, см. О контрактной системе ..., Электр. ресурс). «Применительно к услугам в области дополнительного образования, в соответствии со ст. 13 этого закона, отмечают, В. З. Юсупов, С. В. Ситников, С. В. Вохмянина, речь может идти о действиях, направленных на достижение целей и реализацию мероприятий предусмотренных документами стратегического и программно-целевого планирования (например, государственными или муниципальными программами), выполнением функций и полномочий государственных органов РФ, её субъектов, муниципальных органов и т. д.» (Юсупов, Ситников, Вохмянина, 2015: 131).

Автор настоящей статьи в 2013-2018 гг. руководил экспериментальной работой и участвовал в разработке и реализации целевых образовательных проектов (в том числе в рамках контрактной системы) в Столичной финансово-гуманитарной академии и её филиалах в нескольких городах страны, Кировском филиале академии Федеральной службы исправления наказаний (в настоящее время - Кировский институт повышения квалификации работников Федеральной службы исполнения наказаний России), в нескольких колледжах Москвы, Кировской, Тверской и других областях. В результате нами были выявлены и обоснованы следующие особенности проектно-целевого подхода как способа развития дополнительного профессионального образования:

- реализация социальной, конструктивно-технологической и организационно-деятельностной функции этого подхода в развитии дополнительного образования;

- трансформация цели образовательного заказа в цель образовательного проекта, которая объединяет интересы всех его участников (определение и построение подчинённой цели заказчика иерархизированной системе целей проекта);

- ориентация на выявление, формирования и использование ресурсов вуза под эту систему целей (концентрация ресурсов под цель);

- различение представления о целевом образовательном проекте в его в статистическом виде (как совокупности нормативных документов и учебно-методических материалов) и в динамическом виде (завершённый 
цикл продуктивной деятельности разработчиков и реализаторов проекта); - возможность использования гибких организационных структур проектного типа (проектно-матричная, проектно-модульная и др.).

В ходе исследования были установлены принципы, нормирующие деятельность субъектов целевого образовательного проекта дополнительного образования. В их числе:

- принцип ориентации на социально значимые ценности (ориентирует на ценности, локализованные по отношению к потребностям как заказчика целевого проекта, так и образовательной системе вуза);

- принцип нормативности (соответствие проектируемого объекта законодательным, отраслевым, ведомственным, квалификационным, возрастным, дидактическим и другим нормам осуществления дополнительного образования);

- принцип структурного единства и операциональной заданности целей проекта (предполагает формирование и упорядочение в определённой иерархической системе совокупность целей проекта напрямую связанных с потребностями заказчика, обучающихся и самой организации высшего образования);

- принцип взаимосвязи семиотической и динамических видов целевого проекта (демонстрирует совокупность связей между проектом как организационно-управленческим документом и проектом как завершённым циклом продуктивной деятельности его субъектов, обеспечивающих достижение заданных целей в установленный промежуток времени);

- принцип технологичности выявления, формирования и использования ресурсов (предполагает совокупность последовательно осуществляемых действий по выявлению, распределению и наращиванию ресурсов).

В экспериментальной работе была апробирована технология разработки и реализации целевого образовательного проекта. В качестве примера представим пошаговые действия предпроектного этапа его подготовки.

Первым шагом является изучение документов, отражающих перспективы развития интересующих вуз сфер профессиональной деятельности (стратегии, концепции, программы развития), а так же сопряжённых с этими документами нормативных актов (приказы, распоряжения) и инструктивно-методических материалов (инструкции, рекомендации, наставления и т. д.), регламентирующих содержание и организацию дополнительного профессионального образования категорий работников, повышение квалификации и профессиональная переподготовка которых может осуществляется в рамках государственного задания или заказа на оказание дополнительных образовательных услуг. 
Важной составной частью осуществляемого предпроектного анализа является изучение порядка формирования государственного (муниципального) задания и проведения конкурсов на размещение государственных (муниципальных) заказов оказания услуг в области дополнительного образования. Так, в ходе экспериментальной работы на базе Столичной финансово-гуманитарной академии предметом изучения стал порядок представления, оценки и участия проектов дополнительного профессионального образования в конкурсах, организуемых Департаментом образования города Москвы и Департаментом семейной и молодёжной политики города Москвы. Это позволило, например, разрабатывать программы дополнительного образования руководящих и педагогических работников сферы образования столицы в соответствии с утверждёнными Департаментом образования города Москвы критериями оценки качества таких программ.

Второй шаг предпроектного этапа - это выявление заинтересованных сторон в реализации государственного задания или заказа на оказание дополнительных образовательных услуг. Заинтересованной является сторона, на чьи интересы влияет целевой образовательный проект, например, государственная структура, организация, физическое лицо. У большинства целевых образовательных проектов реально существуют многочисленные заинтересованные стороны, так что первый шаг в управлении ими - знать, кто они. Для учета всех потребностей проекта его команде необходимо как можно более точно определить перечень всех заинтересованных сторон и более чётко очертить их будущие роли. В дальнейшем эта информация может стать базой для выработки критериев оценки успешности проекта, а также для формирования структур управления проектом, определения коммуникационных требований и процедур управления проектной информацией.

В вузе могут существовать определенные на корпоративном уровне стандартные роли (типы) основных заинтересованных сторон проекта. В этом случае функция руководителя и его команды состоят в том, чтобы соотнести эти типы с конкретными группами людей или структурами, задействованными в данном проекте. В случае, если подобной типологии не существует, руководитель проекта и его команда должны её создать с тем, чтобы далее распределить основные роли для каждого из типов заинтересованных сторон.

В ходе эксперимента была разработана матрица типичных заинтересованных сторон в реализации государственного задания (заказа) на оказание дополнительных образовательных услуг (табл. 1). 
Табл. 1. Матрица типичных заинтересованных сторон в реализации государственного задания (заказа) на оказание дополнительных образовательных услуг

\begin{tabular}{|c|l|}
\hline $\begin{array}{c}\text { 3аинтересованная } \\
\text { сторона } 1\end{array}$ & $\begin{array}{l}\text { Государственная структура, наделённая полномочиями по раз- } \\
\text { работке, реализации и финансированию государственного за- } \\
\text { дания (заказа) на оказание дополнительных образовательных } \\
\text { услуг }\end{array}$ \\
\hline $\begin{array}{c}\text { 3аинтересованная } \\
\text { сторона } 2\end{array}$ & $\begin{array}{l}\text { Организация, выступающая в качестве непосредственного за- } \\
\text { казчика дополнительных образовательных услуг, которые ока- } \\
\text { зываются в рамках государственного задания (заказа) }\end{array}$ \\
\hline $\begin{array}{c}\text { 3аинтересованная } \\
\text { сторона } 3\end{array}$ & $\begin{array}{l}\text { Организация, являющаяся работодателем непосредственных } \\
\text { потребителей дополнительных образовательных услуг в рам- } \\
\text { ках государственного задания (заказа) }\end{array}$ \\
\hline $\begin{array}{c}\text { 3аинтересованная } \\
\text { сторона 4 }\end{array}$ & $\begin{array}{l}\text { Категории работников (группы категорий работников) - по- } \\
\text { требителей дополнительных образовательных услуг в рамках } \\
\text { государственного задания (заказа) }\end{array}$ \\
\hline $\begin{array}{c}\text { 3аинтересованная } \\
\text { сторона } 5\end{array}$ & $\begin{array}{l}\text { Организация, предлагающая оказание дополнительных обра- } \\
\text { зовательных услуг в рамках государственного задания (заказа) }\end{array}$ \\
\hline
\end{tabular}

Заинтересованная сторона 1 Государственная структура, наделённая полномочиями по разработке, реализации и финансированию государственного задания (заказа) на оказание дополнительных образовательных услуг

Заинтересованная сторона 2 Организация, выступающая в качестве непосредственного заказчика дополнительных образовательных услуг, которые оказываются в рамках государственного задания (заказа)

Заинтересованная сторона 3 Организация, являющаяся работодателем непосредственных потребителей дополнительных образовательных услуг в рамках государственного задания (заказа)

Заинтересованная сторона 4 Категории работников (группы категорий работников) - потребителей дополнительных образовательных услуг в рамках государственного задания (заказа)

Заинтересованная сторона 5 Организация, предлагающая оказание дополнительных образовательных услуг в рамках государственного задания (заказа)

Третьим шагом в проектной работе стал выбор категорий работников или групп категорий работников, составляющих целевые группы, дополнительное образование которых готов организовать вуз. Выбор этих категорий определялся кадровыми ресурсами вуза, прочностью связей его руко- 
водящего и преподавательского состава с субъектами внешней среды вообще и конкретными категориями работников, в частности.

Результаты экспериментальной работы показали, что наиболее эффективной оказывается проектная деятельность работников вуза, которые активно взаимодействуют непосредственно с данными или смежными с ними целевыми группами. Это позволяет им иметь достаточно объективное представление относительно их потребностей и возможностей, о требованиях работодателей к уровню их профессиональной компетентности, а так же дифференцировать и структурировать потребности обучающихся и запросы работодателей по видам, функциям, должностям категориям работников и т. д.

Так, например, Кировский филиал академии ФСИН, накопив большой опыт взаимодействия со специалистами государственных органов управления и органов местного самоуправления, принимающих участие в формировании, размещении и исполнении государственных и муниципальных заказов, разработал и успешно реализовал дополнительную образовательную программу «Управление государственными и муниципальными заказами». Профессиональный опыт педагогических работников ФСИН нашёл применение в разработке оригинальной программы повышения квалификации частных охранников г. Кирова и Кировской области.

В Столичной финансово-гуманитарной академии опыт взаимодействия с управленческими структурами и организациями социальной сферы столицы сыграл решающую роль в выигранных конкурсах на оказание услуг по организации проектов межведомственной системы повышения квалификации специалистов, работающих в сфере опеки и попечительства. Личный опыт руководящей работы преподавателей СФГА в образовании и в области социальной работы стал залогом качества проектов повышения квалификации руководителей школ.

В ходе расширения масштабов проектной работы получил развитие её кадровый ресурс за счёт преподавателей и сотрудников академии, принимавших активное участие в разработке и реализации целевых образовательных проектов. В практике проектной работы в СФГА использовались возможности временного приёма на работу руководителей проектов под конкретную задачу участия в конкурсах на оказание услуг для государственных и муниципальных нужд, связанных с повышением квалификации работников бюджетных учреждений. В результате, из общего количества проектов, которые готовились и были представлены СФГА на конкурсах по оказанию дополнительных образовательных услуг по повышению квалификации специалистов, работающих в сфере опеки и попечительства, око- 
ло половины оказывалось в числе победителей. При этом авторы проектов, которым не удавалось получить государственное задание или заказ, стремились найти организации, готовые оплатить повышение квалификации своих работников, либо реализовывали проекты за счёт личных средств обучающихся на курсах повышения квалификации и профессиональной переподготовки.

Четвёртым шагом предпроектного этапа целевого образовательного проекта стал анализ имеющихся на рынке дополнительных образовательных услуг предложений дополнительных профессиональных программ, аналогичных или близких по названию к программам, которые, по замыслу инициаторов целевых образовательных проектов, должны были реализоваться в их рамках.

Так, например, программу профессиональной переподготовки «Менеджер образования» предлагали в период экспериментальной работы 11 вузов Москвы. При этом некоторые из них, на начальном этапе эксперимента реализовали эти программы как раз в рамках государственного задания (Московский Институт Открытого Образования, Московский городской педагогический университет и др.). Начиная с 2013 г. функции заказчиков дополнительных образовательных услуг перешли непосредственно образовательным организациям. При этом финансовый ресурс повышения квалификации и профессиональной переподготовки оказался напрямую связанным, например, с количеством обучающихся. В результате принцип финансирования ряда её статей, который образно определялся фразой «деньги идут за обучающимся», распространился и на дополнительное профессиональное образование. Сложившейся ситуацией воспользовались участники эксперимента в Столичной финансово-гуманитарной академии, получая финансирование своих целевых проектов непосредственно от образовательных организаций.

Заключительный пятый шаг предпроектного анализа был связан с разработкой обобщённого описания целевого образовательного проекта и разработкой дополнительной образовательной программы (программ), которую предполагалось реализовать в его рамках.

Проведённое исследование и экспериментальная работа дали основание для следующих выводов:

1. Проектно-целевой подход является наиболее эффективным механизмом развития системы дополнительного профессионального образования в вузе посредством разработки и реализации совокупности реализуемых целевых образовательных проектов.

2. Целевой образовательный проект представляет собой организаци- 
онную форму завершённого цикла деятельности по разработке и предоставлению образовательной услуги в соответствии с запросами конкретного заказчика и потребителей этой услуги.

3. Для современного вуза важно использовать целевые проекты различных источников финансирования: за счет ассигнований федерального бюджета, бюджетов субъектов Российской Федерации и местных бюджетов; бюджетов организаций различных форм собственности, а так же смешанных ресурсов финансирования (например, ресурсов организации и физических лиц).

\section{СПИСОК ЛИТЕРАТУРЫ}

Об образовании в Российской Федерации. Федеральный закон от 29 декабря 2012 г. № 273-Ф3 [Электронный ресурс] // Министерство образования и науки Российской Федерации. URL: минобрнауки.рф/документы/2974 (дата обращения: 17.07.2019).

О контрактной системе в сфере закупок товаров, работ, услуг для обеспечения государственных и муниципальных нужд. Федеральный закон от 5 апреля 2013 г. № 44-Ф3 [Электронный ресурс] // Гарант. URL: http://bas. garant.ru/70353464 (дата обращения 17.07.2019).

Голодова, А. А. (2010) Внедрение методов проектного управления в программах образовательного кластера региона : дисс. ... канд. экон. наук. Волгоград. $173 \mathrm{c.}$

Голышев, И. Г. (2012) Управление интеграцией региональных рынков труда и образовательных услуг в сфере высшего профессионального образования : дис. ... д-ра пед. наук. Казань. 473 с.

Колесникова, И. А. (2005) Педагогическое проектирование : учеб. пособие для высш. учеб. завед. М. : Издат. центр «Академия». 288 с.

Луков, В. А. (2003) Социальное проектирование : учеб. пособие. 3-е изд., перераб. и доп. М.: Изд-во Моск. гуманит.-социальн. академии. 240 с.

Педагогический словарь (2008) : учеб. пособие для студ. высш. учеб. завед. / под ред. В. И. Загвязинского, А. Ф. Закировой. М. : Издат. Центр «Академия». $352 \mathrm{c.}$

Юсупов, В. З., Ситников, С. В., Вохмянина, С. В. (2015) Управление проектом оказания дополнительных образовательных услуг для государственных и муниципальных нужд // Вестник Вятского государственного гуманитарного университета. № 4. С. 129-133. 
Юсупов Виталий Зуфарович - доктор педагогических наук, профессор кафедры педагогики и психологии высшей школы Московского гуманитарного университета. Адрес: 111395, Россия, г. Москва, ул. Юности, д. 5. Тел.: +7 (499) 374-74-59. Эл. адрес: pp.mosgu@mail.ru

Yusupov Vitaly Zufarovich, Doctor of Pedagogy, Professor, Department of Pedagogy and Psychology of Higher Education, Moscow University for the Humanities. Postal address: 5, Yunosti St., Moscow, Russian Federation, 111395. Tel.: +7 (499) 374-74-59 E-mail: pp.mosgu@mail.ru

\section{Для цитирования:}

Юсупов В. 3. Сущностные характеристики проектно-целевого подхода в развитии дополнительного образования [Электронный ресурс] // Научные труды Московского гуманитарного университета. 2019. № 4. URL: http://journals.mosgu.ru/trudy/article/ view/1011 (дата обращения: дд.мм.гг.). DOI: 10.17805/trudy.2019.4.3 